\title{
Programming for Teachers: Supporting Participants in Defining Their Learning Path in a Flexible Online Learning Trajectory Course
}

\author{
Majid Rouhani ${ }^{1 *}$ \\ ${ }^{1}$ Norwegian University of Science and Technology, Norway \\ * Corresponding Author: majid.rouhani@ntnu.no \\ Citation: Rouhani, M. (2020). Programming for Teachers: Supporting Participants in Defining Their Learning \\ Path in A Flexible Online Learning Trajectory Course. International Journal of Childhood Education, 1(1), 13-23. \\ https://doi.org/10.33422/ijce.v1i1.10
}

\begin{abstract}
A fully online and flexible learning-trajectory course for in-service teachers aims to include students with varied programming knowledge, interests, and application needs. The goal is to align the diversity in the target group and flexible learning-trajectories so that every student chooses the right path based on his/her background knowledge and interest. This paper presents a study of helping students reflect on their learning needs and choose the right learningtrajectories in such a course. Students with little or no programming knowledge might find the course content overwhelming, and therefore it might be challenging to find the right learningobjectives/trajectories. We use questionnaires to investigate the prerequisites, competencies, expectations, interests, and needs of each student's local practices. Based on the results, the instructors will support participants through communications channels and webinars to select a learning path that is best fitting each student. Besides, course instructors will identify the "mainstream" in the class and follow them tightly using online webinars. One of the main concerns of providing a flexible learning trajectory course is that many students may struggle to find their learning path and find the course content overwhelming. This paper reflects on how webinars may affect the selection of learning paths for each student.

Key words: online course; programming for teachers; flexible learning trajectories; learning objective; webinar
\end{abstract}

\section{Introduction}

A flexible learning-trajectory course for teachers has the primary objective of providing teachers who are diverse with insight into how they can use programming to create digital solutions. The flexibility of the course makes it possible for students to choose their learning paths. However, students with little or no programming knowledge find the course content overwhelming, and therefore it might be challenging to find the right learning-trajectories. In this case study, we use the course "Applied programming for teachers," which is explained in (Rouhani, Divitini et al. 2019).

This study's central research question is: How can students in such a course reflect on their learning needs and choose the right learning path?

\subsection{Learning Path}

Choosing the right path may depend on a good understanding of the learning needs. Learning might be characterized as the way toward building up a "new ability to do something, and/or an understanding of something that was previously not understood" (Goodyear et al., 2010, p. 6). There can be numerous understandings of the word 'learning,' and these implications cloud conversation about it. The LEPO framework defines the three main components as:

1. The environment which facilitates learning (learning environment)

2. The activities which are part of learning (learning processes), and 
3. The knowledge, behaviors, skills, or understanding, which can be demonstrated

(learning outcomes).

Two general participants collaborate with these three segments, the student and the educator, and all components exist in a more extensive, educational setting (Phillips et al., 2012).

When a participant has identified the areas of interest and the level of programming skills, which might be linked to subjects taught in school, he/she need to define a path to follow in the course. In this study, we have suggested the use of webinars, videos, and communication channels provided as a way of supporting this process.

The Norwegian Directorate (UDIR) defines digital skills as one of five essential skills for Education and Training. Competency goals and assessment-form for each subject are defined (Utdanningsdirektoratet, 2020). Digital literacy and skills are further defined for schools at IKT Plan (iktplan.no, 2020). We suggest that each student in the flexible learning trajectory course get a clear understanding of competency goals and assessment-forms predefined by UDIR to be able to relate these to different topics of the course.

In addition to these predefined competency goals, webinars can be used to support students in selecting the right learning path. Webinars can be utilized in advanced education as one of the numerous online tools in blended learning (Mohorovičić et al., 2011). Anecdotal proof shows that mixed learning offers more choices and is more effective (Singh, 2003). NIIT (National Institute of Information Technology) classifies blended learning into three models. Skill-driven learning, which consolidates self-managed learning with the teacher or facilitator to create explicit knowledge and abilities. Attitude-Driven, which blends different events and delivery media to create particular behaviors. Attitude-Driven, which blends different events and delivery media to create particular behaviors. Competency-driven learning, which combines performance support tools with knowledge management resources and mentoring to develop workplace competencies. (Valiathan, 2002).

The US study of over a thousand research pieces conducted between 1996 and 2008 concluded that blended learning does offer learning advantages; however, the benefits are not due to the technology per se but relate to time spent in education, curriculum design, and pedagogy. (Means et al., 2009).

A student in this course (teacher) can set up a proper learning path based on the following actions: Identify digital skills specified by the government (e.g., UDIR), get a clear understanding of competency goals, and set up a learning path using webinars and other communication tools in the course.

\subsection{Personalising Education}

Customizing instructing and learning implies that the "learner is central" because the requirements, interests, backgrounds, and learning styles of individuals are the focus. People's learning styles are put in the center, and students are more engaged through more "decision and voice" in their learning (Keamy et al., 2007). Increasingly, Information and Communications Technology (ICT) is the enabler for personalizing learning by giving students greater diversity in their education and more flexible, personalized learning spaces (Brown et al., 2014).

Keamy et al. (2007) explain in their study that most of the students enjoyed the increased flexibility in their learning and their assessment. What came out strongly is that students want their personalized learning not only in the form of online activities but predominantly through interactive, collaborative, well-structured learning activities in a face-to-face environment. Blended learning and flipping the classroom are teaching models that leverage the flexibility of online education and the social interaction and collaborative learning of the face-to-face classroom (Keamy et al., 2007).

We expect students to be diverse in their prior programming knowledge and interest in the application of programming. There is, therefore, an assumption that some of the students will 
not be able to manage setting up their learning paths. In this study, we aim to answer the following research question:

RQ1: Can webinars linked to the modules in a flexible learning-trajectory course, help students find the right learning path?

\section{Methodology}

This study is based on the previous work (Rouhani et al., 2019) done by the author on the design of a flexible learning trajectory course for teachers. A flexible course may present challenges for participants when setting up their learning paths. The flexible modules usually contain many topics since the objective of the module is to provide a wide variety of subjects, which does not apply to all participants. Figure 1 shows how a flexible learning trajectory course can be organized. Modules 1 and 2 are mandatory to all participants, while modules 3 and 4 with corresponding exercises 3 and 4 are flexible.

We held a webinar related to each of the four modules (both mandatory and flexible modules). We used a questionnaire to get feedback from participants on how these webinars have helped them get a better overview and a better understanding of the topics discussed in each module.

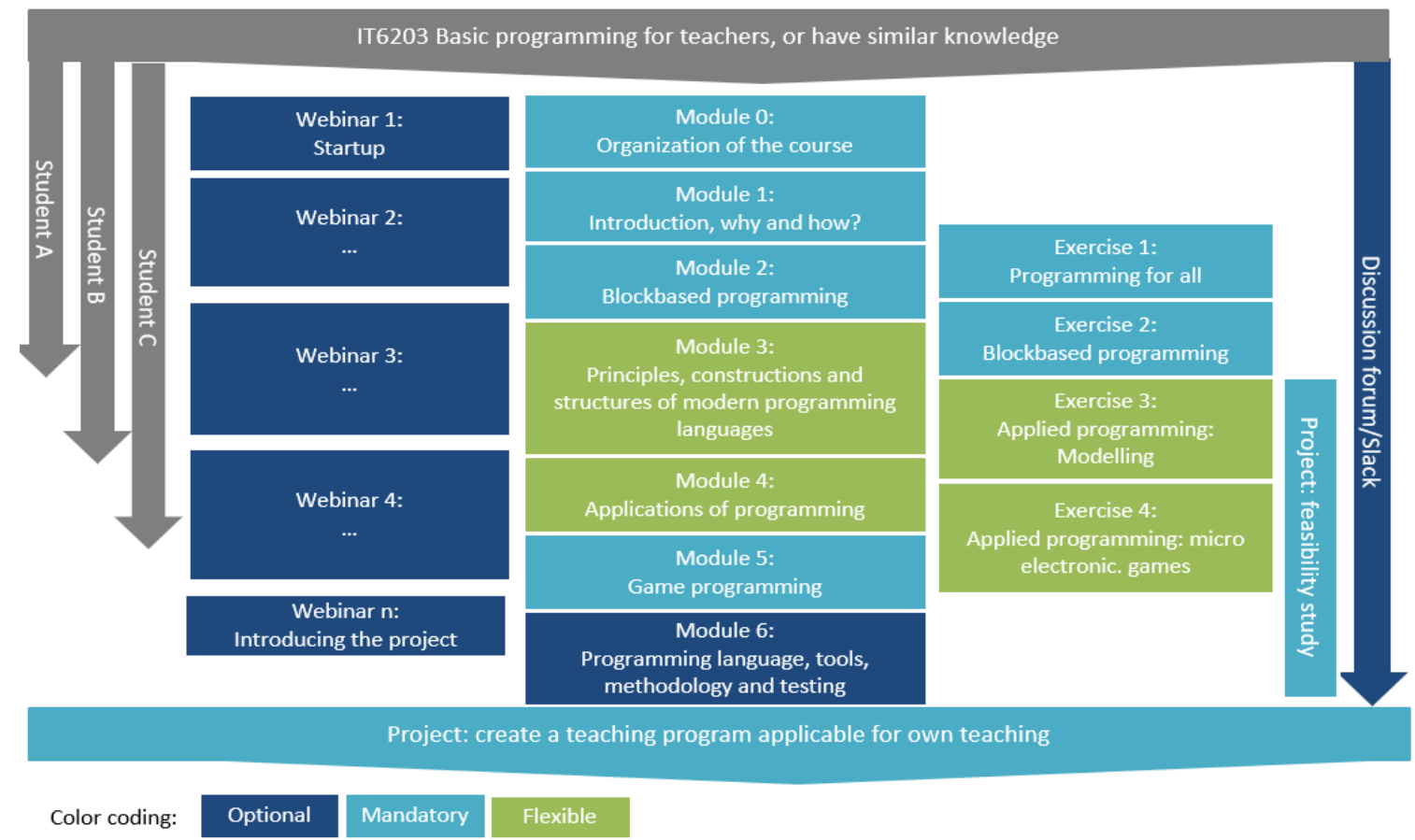

Figure 1. Organisation of a flexible learning trajectory course

The admission process for the course "IT6203 Basic programming for teachers" (See Figure 1) and "IT6204 Applied programming for teachers" (which is the course with flexible learning trajectory and is addressed in this paper) are the same. That is, all students admitted to one class can automatically continue with the next one. There were 200 students enrolled in the course. The pre-course survey ran after the introductory lecture in "IT6203 Basic programming for teachers", received 186 responses (a rate of 93\%). Figure 2 shows that $78 \%$ are teaching at upper secondary school (videregaaende), and $20.4 \%$ teach at lower secondary school (ungdomsskole). 


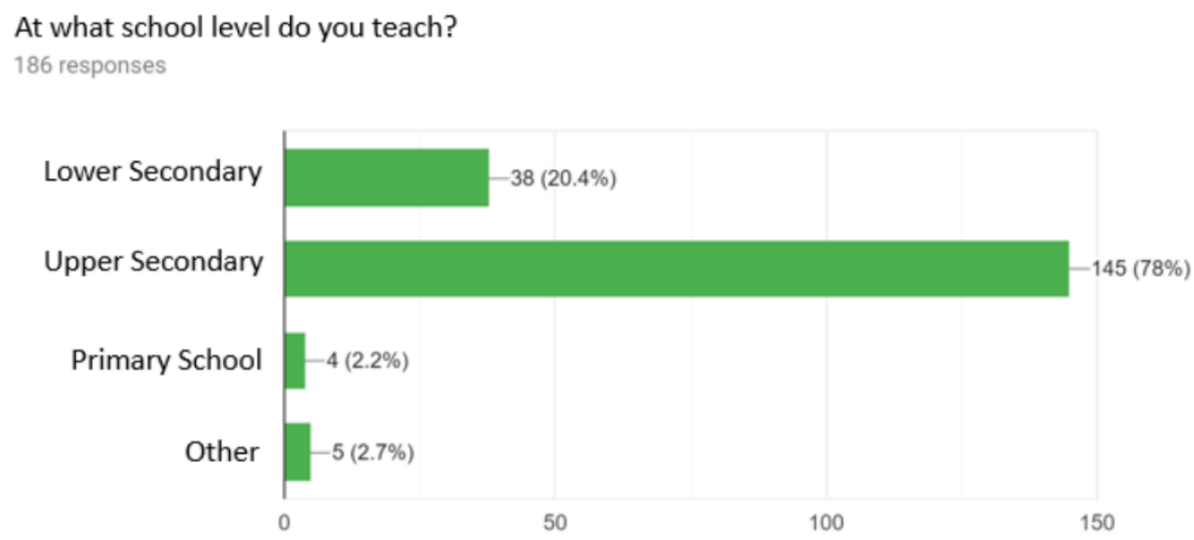

Figure 2. School level participants are teaching

Most teachers (84.9\%, see Figure 3), are teaching mathematics and natural sciences (Realfag). This group of students is almost homogeneous since most of them are teaching in the same area. The focus in webinars is, therefore, to give guidance to this group. Other groups of teachers are teaching in many different subjects and may need support to find the right learning path.

\section{What subject to you teach in?}

186 responses

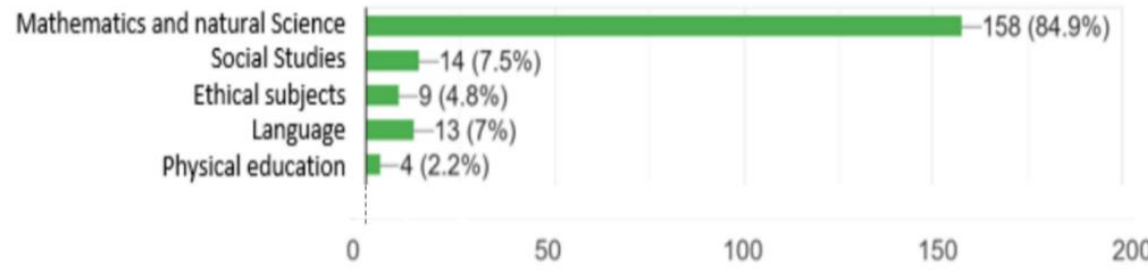

Figure 3. Showing what subjects' participants are teaching

At the starting point of "IT6204 Applied programming for teachers", the number of students was 173 , a drop rate of $13.5 \%$.

We created one questionnaire for modules 1-4. Further, we omitted module 6 since it is optional and embedded module 5 in module 4 to reduce the number of surveys. Module 0 is not included in this study as it describes the organization and some practical information about the course. Exercise 1 was about programming pedagogy. The questions that participants had to answer related to why should everyone learn to program, and what are the challenges? And how can we set the framework for learning programming? Students answer these questions both by getting into the tutorials (Guzdial, 2015) and reflecting on these topics. It might be of interest to study these reflections and follow those throughout the course to see whether their opinions are affected. Therefore, it becomes interesting to analyse this in a separate study. We will examine the student submissions in a separate article.

Conducting multiple surveys in a course where participants are already in-service teachers can be challenging. We decided to reduce the number of questions asked to increase participation. The number of participants in each survey is shown in Table 1.

The first question in the questionnaire was: "Anonymized data from the survey can be used in research related to the subject. Select "Yes" and click "Next" to participate in the survey". Many of the students decided not to answer the questions. We included only completed surveys and did not differentiate between those who chose not to continue based on the first question 
and those that did not click the survey link at all. Table 1 show number of responses in each questionnaire. Students answered each question on a scale from 1 to 5 , where one means completely disagree, and five means completely agree. Here are the questions from the questionnaire:

Q1: Module 1(programming pedagogy) has been helpful and has given me insight into why I should learn to program.

Q2: I attended or saw the recording on Webinar 1, which was informative and gave me a good understanding of the course structure.

Q3: Module 2 (block programming) has been helpful. I have gained a good understanding of what block programming is and how I can use it to teach programming at my school.

Q4: I attended or saw the recording at Webinar 2, which was informative and gave me a good understanding of: (I) what block programming is and how I get started. (II) debugging code (run the program line by line to find errors/understanding what's going on).

Q5: I find Exercise 2 helpful and learned how to write block-based programming.

Q6: Module 3 (principles, constructions, and structures of modern programming) has been useful and has expanded my programming skills through applications.

Q7: I attended or saw the recording at Webinar 3, which was informative and helped me to understand the topics in module 3 better.

Q8: I find Exercise 3 helpful and have learned how to apply modulation/web design programming.

Q9: Module 4 (application of programming) has been useful and has expanded my programming skills through applications in modelling, web design, and microelectronics.

Q10: I attended or saw the recording at Webinar 4, which was informative and helped me to understand the topics in module 4 better.

We divided these questions into the following surveys: Survey I: Questions 1-2, Survey II: Questions 3-5 and Survey III: Questions 6-10.

Table 1.

Responses per questionnaire

\begin{tabular}{lll}
\hline Survey & \#Responses & Response rate $(\%)$ \\
\hline Survey I & 41 & $23 \%$ \\
Survey II & 45 & $26 \%$ \\
Survey III & 16 & $9 \%$ \\
\hline
\end{tabular}

Assessment criteria are a scale from 1 to 5, where one means "disagree entirely", and five means "agree entirely"

Table 2.

Summary of data

\begin{tabular}{cccccccc}
\hline Scale & Webinars & Modules & Exercises & Total & Mean & Median & Std.Dev \\
\hline 1 & 4 & 2 & 1 & 7 & 2.33 & 2.00 & 1.53 \\
2 & 9 & 5 & 4 & 16 & 5.33 & 5.00 & 1.53 \\
3 & 24 & 25 & 9 & 58 & 19.33 & 24.00 & 8.96 \\
4 & 35 & 54 & 25 & 114 & 38.00 & 35.00 & 14.73 \\
5 & 42 & 31 & 21 & 94 & 31.33 & 31.00 & 10.50 \\
\hline
\end{tabular}

\section{Results}

Students' views and experiences with flexible learning and assessment related to webinars, course modules, and exercises are gathered using three surveys and presented in the below sections. 


\subsection{Webinars}

Figure 4 shows each webinar. The $\mathrm{X}$-axis is showing the score, which can be from 1 to 5 , and $\mathrm{Y}$-axis is showing the number of responses for each rating.

The topic for webinar one was to introduce the overall course structure, clarify the expectations of both students and instructors. A total of four students do not agree to Q2, while 30 students agree, and the rest (6) do neither agree nor disagree. A rate of $81 \%$ agrees with the claim in Q2. The topic of webinar two was block-based programming, organization of module two, and debugging. Debugging was introduced in this session to prepare students for the next module, which is text-based programming. A total of four students do not agree to Q4, while 33 students agree, and the rest (8) do neither agree nor disagree. A rate of $73.3 \%$ agrees with the claim in Q4. The topic of webinar three was data structures (file-handling, queues) and object-oriented programming. A total of three students do not agree to Q7, while 7 students agree, and the rest (5) do neither agree nor disagree. A rate of $47 \%$ agrees with the claim in Q7. The topic of webinar four was application of programming with focus on modelling. A total of two students do not agree to Q10, while 7 students agree, and the rest (5) do neither agree nor disagree. A rate of $50 \%$ agrees with the claim in Q10.

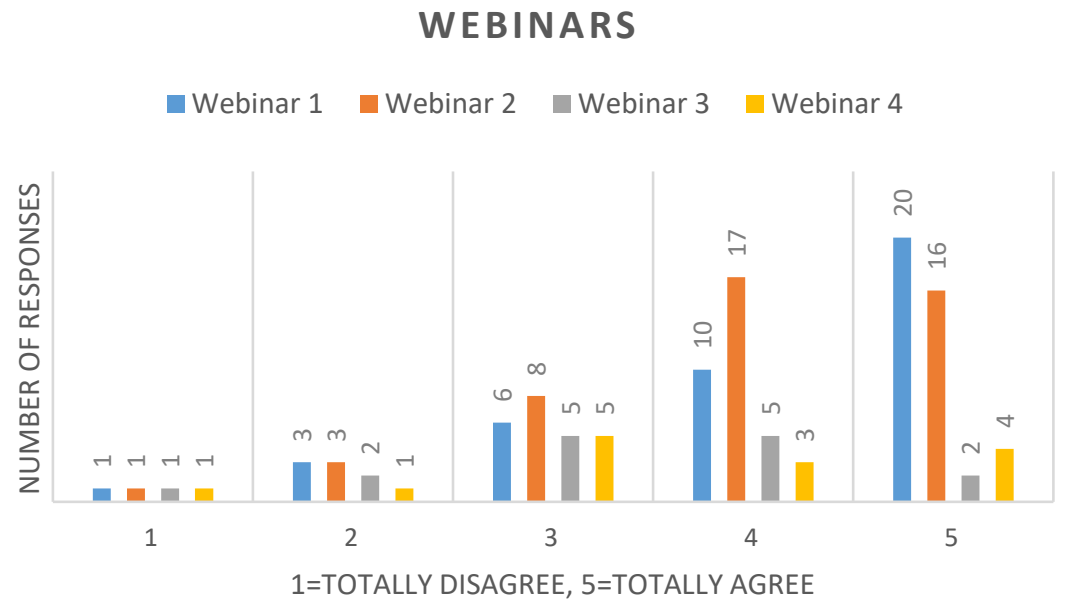

Figure 4. Result of all surveys related to webinars

Figure 5 shows mean and median for each webinar in addition to the total for all webinars. Mean and total for all webinars are four, which gives a rate of $80 \%$.

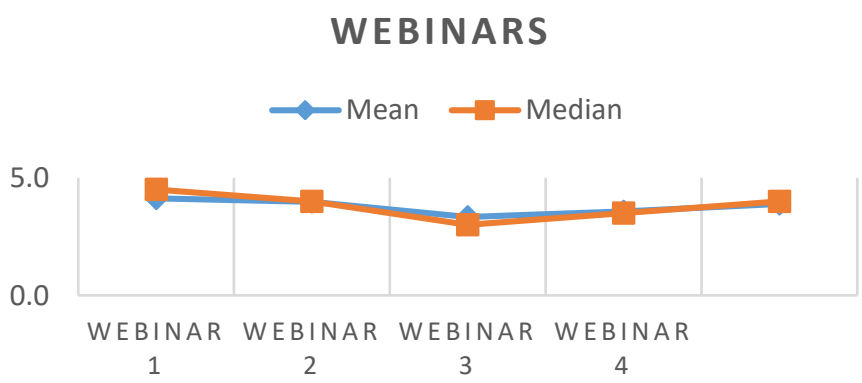

Figure 5. Mean and median of webinars

\subsection{Modules}

The topic for module one is programming pedagogy. A total of two students do not agree to Q1, while 30 students agree, and the rest (9) do neither agree nor disagree. A rate of $73.2 \%$ agrees with the claim in Q1. The topic for module two is block-based programming. A total of five students do not agree to Q3, while 33 students agree, and the rest (7) do neither agree nor 
disagree. A rate of $73.3 \%$ agrees with the claim in Q3. The topic for module three is principles, constructions, and structures of modern programming. One student does not agree to Q6, while 10 students agree, and the rest (6) do neither agree nor disagree. A rate of 59\% agrees with the claim in Q6. The topic for module four is application of programming. A total of 12 students do agree to Q9, and the rest (4) do neither agree nor disagree. A rate of $75 \%$ agrees with the claim in $\mathrm{Q} 9$.

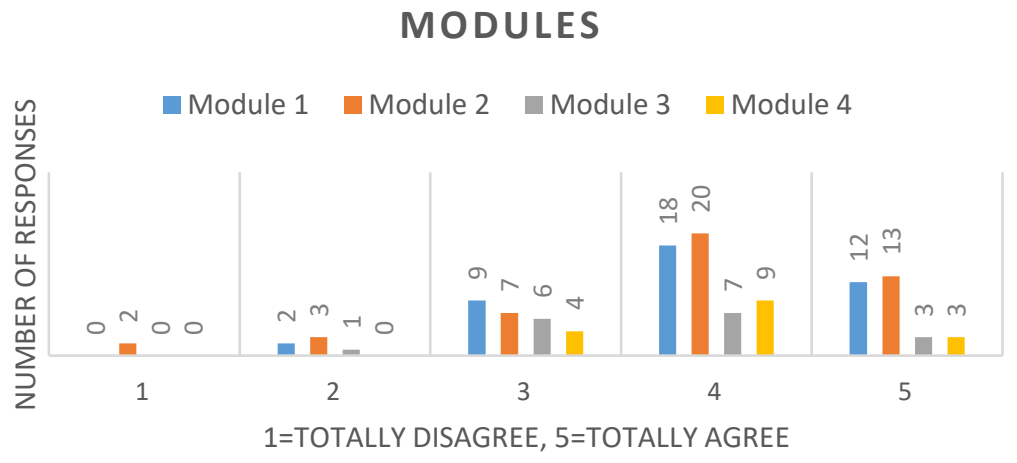

Figure 6. Number of responses per module

Figure 7 shows mean and median for each module in addition to the total for all modules. Mean and total for all modules are four, which gives a rate of $80 \%$.

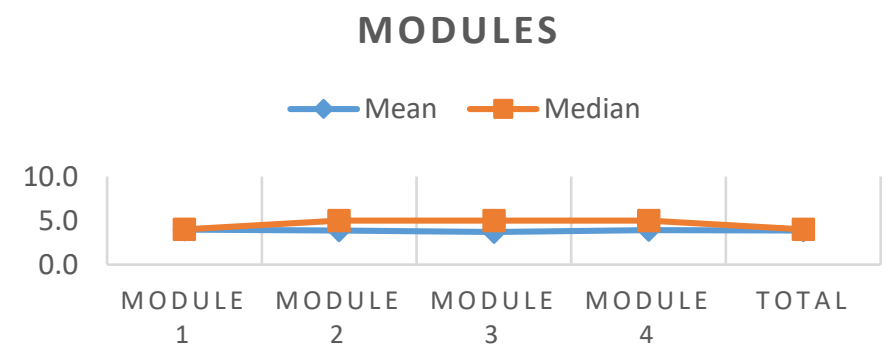

Figure 7. Mean and median of modules

Since participants are in-service teachers, we expected that a low number of teachers could join the webinars live. However, to make sure that as much as possible have the opportunity to participate, we used a doodle form to find the most suitable time. The choice that suited most had 27 votes.

Table 3 shows statistics over watched webinars. Each webinar has been recorded and split into minor videos (2-15 minutes in length) and made available for participants to watch later.

Table 3.

Watched webinars (live \& recording)

\begin{tabular}{lcccc}
\hline & Live & Afterwards & Total watched & Rate \\
\hline Webinar 1 & 29 & 136 & 165 & $95 \%$ \\
Webinar 2 & 13 & 96 & 109 & $63 \%$ \\
Webinar 3 & 16 & 69 & 85 & $49 \%$ \\
Webinar 4 & 9 & 33 & 42 & $24 \%$ \\
Mean & 17 & 83 & 100 & $58 \%$ \\
Std.dev & 7.5 & 37 & 44 & $26 \%$ \\
\hline
\end{tabular}

Calculated rates for each webinar show that $95 \%$ have seen webinar 1 . This number decreases noticeably in webinars 2,3 , and 4 . 


\subsection{Exercises}

Figure 8 shows number of responses per exercise. The topic for exercise two is block-based programming. One student did not agree to Q5, while 30 students agree, and the rest (9) do neither agree nor disagree. A rate of $73.2 \%$ agrees with the claim in Q1. The topic for module two is block-based programming. A total of five students do not agree to Q3, while 33 students agree, and the rest (7) do neither agree nor disagree. A rate of $73.3 \%$ agrees with the claim in Q3. The topic for module three is principles, constructions, and structures of modern programming.

\section{EXERCISES}

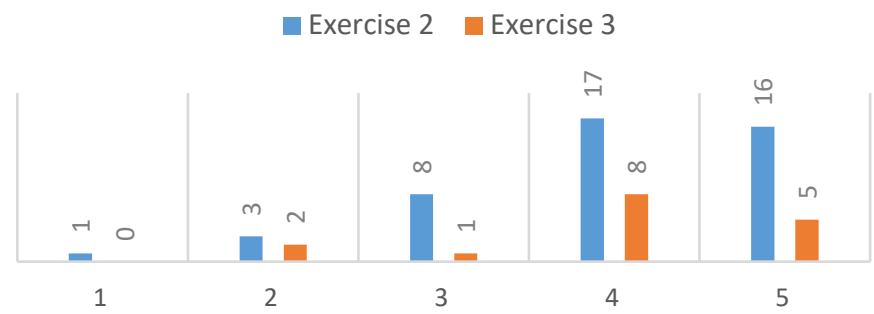

Figure 8. Number of responses per exercise

Figure 9 shows mean and median for each exercise in addition to the total for all exercises.

\section{EXERCISES}

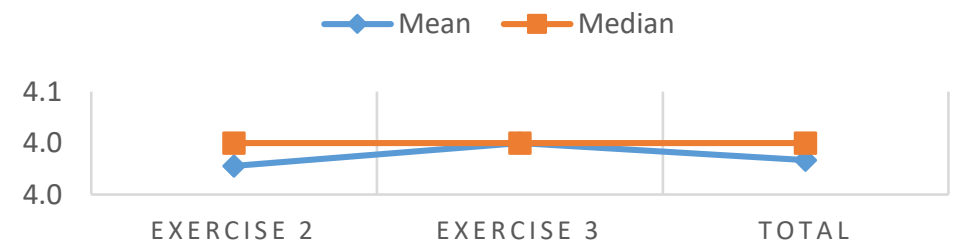

Figure 9. Mean and median of exercises

\subsection{Qualitative data}

In all surveys, students could write a free text comment and give us any other positive or negative feedback. Some of these comments are listed below:

\section{Positive:}

- Good information. Very good that so much of the work requirements through the course are out there already available, then it is easier to organize time.

- I think this has been excellent in terms of information. I appreciate that I can work on what is useful to me and that all information is available from day 1 . Very well organized!

- Nice that it is optional which modules to immerse yourself

- The module provided useful guidelines for finding good quality information. See no urge for improvement.

- I had tried some block programming beforehand, so it was easy to get started. What was most useful were ways to utilize micro: bit. It was also helpful with the debugging section in Python.

- I like the course very well. Very varied and motivating

Negative:

- I think we will learn a lot about programming and teaching programming in the course but fear that we will not learn anything that will help me teach math in a new way. 
- I think it is more appropriate in upper secondary to write code myself. I would instead learn to use Matplotlib, and more features in numpy.

- I have tried working with several modules early for various reasons. It seems a little unclear what to do on the different exercises. Besides, there is a lot of links to online sources, so you can almost feel lost. Could have been a slightly narrower selection of sources.

- I do not quite see the connection between lectures/reading material and the tasks in exercises. I have spent a lot of time figuring out microelectronics on my own and haven't had time to read or try to learn what is being reviewed.

Even though we received mostly positive feedback, there was also negative feedbacks indicating that webinars do not necessarily help all students in finding the right learning path.

\section{Discussion}

Programming can be fun, interesting, and challenging (Simon et al., 2009), but it can also be very difficult for beginners of all ages. In addition to the challenges of learning to form structured solutions to problems and understanding how programs are executed, beginning programmers also have to learn a rigid syntax and rigid commands that may have seemingly arbitrary or perhaps confusing names (Kelleher et al., 2005). Providing a flexible learning trajectory course may add even more complexity (Rouhani et al., 2019) since it contains many different topics with varying levels of difficulty. There is limited evidence in the literature that flexible programming course for in-service teachers, makes programming fun, interesting and leads to better marks and learning outcomes. However, my intuitions in letting teachers choose relevant areas to the application of programming are that it can make it both fun and exciting. This study provided useful insight into the attitudes of participants towards the approach of flexible learning trajectory teaching. The results show that most participants are confident with the modules (1-4), webinars (1-4), and exercises (1-2) in the class. We believe that the use of webinars in this course has helped most of the participants to select the right learning path. The objectives of webinars were to help all participants choose the right topics and guide students through the modules. Our study adds to the "compelling evidence of the importance of encouraging student control over the learning process as a whole"(McLoughlin et al., 2010). It also shows that personalizing learning is successful in improving student engagement and the students' learning experiences in higher education (Jones et al., 2012).

Another outcome is that webinars have not helped all participants in finding their learning path. In-service teachers are not flexible in their availability for live webinars(Rouhani et al., 2019). A maximum of $17 \%$ (Table 3) have been able to join webinars live. The recordings were therefore available for later use. We split videos into various shorter videos based on the topic. Some participants watched only a subset of videos and hence did not get the overall view, which was the main objective of webinars. We believe this has led to confusion and difficulties in finding what to do in the course.

As one teacher said, "...I have spent a lot of time figuring out microelectronics on my own and haven't had time to read or try to learn what is being reviewed" - time seems to be critical for this group of participants to be able to follow the course as intended. It may be appropriate to have pre-defined learning paths based on the education levels (elementary, secondary) (Guzdial, 2015) and subjects they are teaching in so that participants can follow.

\section{Conclusion}

The majority of the participants enjoyed webinars as a supporting tool in finding their learning path in the flexible learning trajectory course. In particular, students enjoyed the availability of course material (topics \& exercises) from the start and useful information about how the course is structured and how they can find information. In this study, we have shown that webinars 
can play a constructive rule in linking different topics in a flexible learning-trajectory course to set up a customized learning path for each student. However, time is critical for in-service teachers, and few can join the webinars live. Personalized learning is still in its early stages. Still, it is a realistic pathway towards making education more flexible and learning-centered, and we believe the use of webinars to some extend can help students identify their learning path in a flexible learning trajectory context.

Some areas of future research on this topic are the predefining learning path for in-service teachers, which might help students finding the learning path.

\section{References}

Brown, A., \& Green, T. (2014). Issues and trends in instructional technology: Maximizing budgets and minimizing costs in order to provide personalized learning opportunities. In Educational media and technology yearbook (pp. 11-24): Springer. https://doi.org/10.1007/978-3-319-06314-0_2

Goodyear, P., \& Retalis, S. (2010). Technology-enhanced learning. Rotterdam: Sense Publishers, 6.

Guzdial, M. (2015). Learner-centered design of computing education: Research on computing for everyone. Synthesis Lectures on Human-Centered Informatics, 8(6), 1-165. https://doi.org/10.2200/s00684ed1v01y201511hci033

iktplan.no. (2020). Digital kompetanse og digitale ferdigheter. Retrieved from https://www.iktplan.no/

Jones, M. M., \& McLean, K. J. (2012). Personalising Learning in Teacher Education through the Use of Technology. Australian Journal of Teacher Education, 37(1), 75-92. https://doi.org/10.14221/ajte.2012v37n1.1

Keamy, R. L., Nicholas, H. R., Mahar, S., \& Herrick, C. (2007). Personalising education: from research to policy and practice.

Kelleher, C., \& Pausch, R. (2005). Lowering the barriers to programming: A taxonomy of programming environments and languages for novice programmers. ACM Comput. Surv., 37(2), 83-137. https://doi.org/10.1145/1089733.1089734

McLoughlin, C., \& Lee, M. J. (2010). Personalised and self regulated learning in the Web 2.0 era: International exemplars of innovative pedagogy using social software. Australasian Journal of Educational Technology, 26(1). https://doi.org/10.14742/ajet.1100

Means, B., Toyama, Y., Murphy, R., Bakia, M., \& Jones, K. (2009). Evaluation of evidencebased practices in online learning: A meta-analysis and review of online learning studies.

Mohorovičić, S., Lasić-Lazić, J., \& Strčić, V. (2011). Webinars in higher education. Paper presented at the 2011 Proceedings of the 34th International Convention MIPRO.

Phillips, R., McNaught, C., \& Kennedy, G. (2012). Evaluating e-learning: Guiding research and practice: Routledge.

Rouhani, M., Divitini, M., Vujosevic, V., Stai, S., \& Olstad, H. A. (2019). Design of a programming course for teachers supporting flexible learning trajectories. Paper presented at the Proceedings of the 8th Computer Science Education Research Conference, Larnaca, Cyprus. https://doi.org/10.1145/3375258.3375263

Simon, B., Hanks, B., McCauley, R., Morrison, B., Murphy, L., \& Zander, C. (2009). For me, programming is. Paper presented at the Proceedings of the fifth international workshop on 
Computing education research workshop, Berkeley, CA, USA. https://doi.org/10.1145/ 1584322.1584335

Singh, H. (2003). Building effective blended learning programs. Educational TechnologySaddle Brook Then Englewood Cliffs NJ-, 43(6), 51-54.

Utdanningsdirektoratet. (2020). Digitale ferdigheter som grunnleggende ferdighet. Retrieved from https://www.udir.no/laring-og-trivsel/lareplanverket/grunnleggende-ferdigheter/digit ale-ferdigheter-rammeverk/

Valiathan, P. (2002). Blended learning models. Learning circuits, 3(8), 50-59. 